\title{
Body Mass Index, Weight Loss, and Mortality Risk in Advanced-Stage Non-Small Cell Lung Cancer Patients: A Focus on EGFR Mutation
}

\author{
Yu-Mu Chen ${ }^{1,2}$, Chien-Hao Lai ${ }^{1}$, Chiung-Yu Lin ${ }^{1}$, Yi-Hsuan Tsai ${ }^{1}$, Ya-Chun Chang ${ }^{1}$, Hung-Chen Chen ${ }^{1}{ }^{1}$, \\ Chia-Cheng Tseng ${ }^{1}$, Huang-Chih Chang ${ }^{1}$, Kuo-Tung Huang ${ }^{1}$, Yung-Che Chen ${ }^{1} \mathbb{D}$, Wen-Feng Fang ${ }^{1,3,4}$, \\ Chin-Chou Wang ${ }^{1}$, Tung-Ying Chao ${ }^{1}$ and Meng-Chih Lin ${ }^{1,5, *}$
}

1 Department of Internal Medicine, Division of Pulmonary and Critical Care Medicine, College of Medicine, Chang Gung University, Kaohsiung Chang Gung Memorial Hospital, Niaosung, Kaohsiung 83301, Taiwan; blackie@cgmh.org.tw (Y.-M.C.); lieo@cgmh.org.tw (C.-H.L.); chiungyu@cgmh.org.tw (C.-Y.L.); yhtsai@cgmh.org.tw (Y.-H.T.); y7817@cgmh.org.tw (Y.-C.C.); chc1106@cgmh.org.tw (H.-C.C.); cctseng@cgmh.org.tw (C.-C.T.); kuan2101@yahoo.com.tw (H.-C.C.); jelly@cgmh.org.tw (K.-T.H.); yungchechen@yahoo.com.tw (Y.-C.C.); wenfeng@cgmh.org.tw (W.-F.F.); ccwang52@cgmh.org.tw (C.-C.W.); tychao@cgmh.org.tw (T.-Y.C.)

2 Graduate Institute of Clinical Medical Sciences, College of Medicine, Chang Gung University, Kaohsiung Chang Gung Memorial Hospital, Kaohsiung 83301, Taiwan

3 Department of Respiratory Therapy, College of Medicine, Chang Gung University, Kaohsiung Chang Gung Memorial Hospital, Kaohsiung 83301, Taiwan

check for

updates

Citation: Chen, Y.-M.; Lai, C.-H.; Lin, C.-Y.; Tsai, Y.-H.; Chang, Y.-C.; Chen, H.-C.; Tseng, C.-C.; Chang, H.-C.; Huang, K.-T.; Chen, Y.-C.; et al. Body Mass Index, Weight Loss, and Mortality Risk in Advanced-Stage Non-Small Cell Lung Cancer Patients: A Focus on EGFR Mutation. Nutrients 2021, 13, 3761. https://doi.org/ 10.3390/nu13113761

Academic Editor:

Riccardo Caccialanza

Received: 6 October 2021

Accepted: 22 October 2021

Published: 24 October 2021

Publisher's Note: MDPI stays neutral with regard to jurisdictional claims in published maps and institutional affiliations.

Copyright: () 2021 by the authors. Licensee MDPI, Basel, Switzerland. This article is an open access article distributed under the terms and conditions of the Creative Commons Attribution (CC BY) license (https:// creativecommons.org/licenses/by/ $4.0 /)$.
4 Department of Respiratory Care, Chang Gung University of Science and Technology, Chiayi 61363, Taiwan

5 Respiratory Center of Excellence, Chang Gung Medical Insititute, Kaohsiung 83301, Taiwan

* Correspondence: linmengchih@hotmail.com; Tel.: +886-7-7317123

\begin{abstract}
Body mass index (BMI) influences the prognosis of patients with non-small cell lung cancer (NSCLC), including both early-stage and late-stage NSCLC patients that are undergoing chemotherapies. However, earlier research on the relationship between BMI and survival in patients taking epidermal growth factor receptor (EGFR)-tyrosine kinase inhibitors (TKIs) yielded contradictory results. These publications either had a limited number of patients or were getting TKIs in various lines of therapy, which might explain why the outcomes were contradictory. As a result, we undertook retrospective study to examine the effect of BMI on survival outcomes in patients with advanced EGFR mutant NSCLC receiving first-line EGFR-TKIs. We also compared the findings to those with wild-type EGFR. Between November 2010 and March 2014, 513 patients with advanced NSCLC were enrolled in the study. According to the adjusted BMI cut-off point for Asia, 35 out of $513(6.8 \%)$ patients were underweight $\left(\mathrm{BMI}<18.5 \mathrm{~kg} / \mathrm{m}^{2}\right)$, whereas $197(38.4 \%)$ were overweight $\left(\mathrm{BMI}>24 \mathrm{~kg} / \mathrm{m}^{2}\right)$. Overweight patients with wild-type EGFR exhibited longer progression-free survival (4.6 vs. 2.1 months, $p=0.003$ ) and overall survival (OS) (8.9 vs. 4.3 months, $p=0.003$ ) than underweight patients. Overweight patients with EGFR mutations had a longer OS than normal-weight patients ( 23.0 vs. 20.2 months, $p=0.025)$. Bodyweight reduction was related to a shorter OS in both the mutant EGFR patients (17.1 vs. 30.5 months, $p<0.001$ ) and the wild-type EGFR patients (7.8 vs. 18.7 months, $p<0.001$ ). In conclusion, advanced stages NSCLC patients with a lower BMI and early weight loss had a worse outcome that was independent of EGFR mutation status.
\end{abstract}

Keywords: body mass index; weight loss; non-small cell lung cancer; tyrosine kinase inhibitor

\section{Introduction}

Lung cancer is the most frequent disease that is diagnosed and is the main cause of cancer mortality globally [1]. Being overweight has been identified as a risk factor for the majority of malignancies [2-5]. The incidence of lung cancer, on the other hand, was found to have an inverse relationship with BMI [2-5]. Higher body mass index (BMI) has been linked to a better prognosis in patients with early-stage non-small cell lung cancer 
(NSCLC) [6], as well as in NSCLC patients who were undergoing chemotherapies [7-9]. Lung cancer treatments have advanced considerably in recent years [10]. The discovery of EGFR-tyrosine kinase inhibitors (TKIs) enhanced the life quality and survival in advanced NSCLC patients with sensitive EGFR mutations [11-13]. Previous research has discovered several predictors of EGFR-TKI treatment response, including performance status and metastatic locations [14]. Previous research, however, found conflicting results regarding the baseline BMI and the survival of patients taking EGFR-TKIs. One study found that a lower BMI was linked to a longer progression-free survival (PFS) in EGFR-TKI patients [15], however, another study found that a lower BMI was associated with worse survival results [16]. The study found that BMI did not affect the effectiveness of EGFR-TKIs [17]. These trials either were comprised of a limited number of patients or those who got TKIs after first-line treatment. As a result, we conducted a retrospective study to assess the influence of BMI and bodyweight reduction on survival outcomes in patients with EGFR mutant, advanced-stage NSCLC who had received first-line EGFR-TKIs. We also compared the findings to patients with wild-type EGFR.

\section{Materials and Methods}

\subsection{Study Population}

A retrospective study was performed at Kaohsiung Chang Gung Memorial Hospital, a university-affiliated medical facility, between 1 November 2010, and 30 March 2014. Patients were followed up on until 31 December 2015. Patients that were over the age of 18 with cytologically or histologically confirmed, newly diagnosed stage IIIB or IV NSCLC, and who had EGFR mutation testing were eligible. Patients who did not have baseline BMI data or were lost to follow-up were excluded. Within one month after starting therapy, baseline clinical profiles, chest computed tomography, bone scintigraphy, and brain magnetic resonance imaging were all evaluated. We defined underweight and overweight patients using a modified BMI cut-off criteria for Asians [18-20]. According to BMI, patients were classified into three groups: underweight (BMI $18.5<\mathrm{kg} / \mathrm{m}^{2}$ ), normalweight (BMI 18.5-24 kg/m²), and overweight (BMI $>24 \mathrm{~kg} / \mathrm{m}^{2}$ ). A bodyweight loss of more than $5 \%$ was classified when it occurred within three months of the diagnosis of lung cancer [21]. The study was authorized by the Kaohsiung Chang Gung Memorial Hospital's Institutional Review Board, with permission number 104-7011C. Informed consent was not required.

\subsection{Testing of EGFR Mutation Status}

Bronchoscopy, pleural effusion cytology, computed tomography (CT)-guided biopsy, and surgical techniques were used to acquire the tumor tissue. The EGFR mutation was frequently tested in patients with a variety of histologic subtypes, including adenocarcinoma, adenosquamous cell carcinoma, large cell carcinoma, and NSCLC that was not otherwise specified. It was also performed on patients with squamous cell carcinoma who had never smoked. Testing was evaluated with the QIAGEN EGFR RGQ PCR Kit's SCORPIONS and Amplified Refractory Mutation System (ARMS) [22]. The EGFR testing results were obtained from the patient's health records.

\subsection{Evaluation of Disease Status}

Every $2-4$ weeks, chest radiography was performed to assess the tumor response, and every 2-3 months, a chest CT was employed. The disease state was assessed by the physician using the Response evaluation criteria in solid tumors criteria 1.1 [23].

The primary and secondary endpoints were PFS and overall survival (OS). PFS was defined as the time between the first day of EGFR-TKI or chemotherapy treatment and disease progression, the last day of follow-up, or death before tumor progression. The time from the first day of EGFR-TKI or chemotherapy and death or the last follow-up was referred to as the OS. 


\subsection{Statistical Analyses}

MedCalc was used for statistical analysis (Version 14). A Student's t-test or MannWhitney U test was used to evaluate the continuous variables while a Chi-square test or Fisher's exact test was used to evaluate the categorical variables between patients with or without EGFR mutation. A one-way ANOVA was used to evaluate the continuous variables in the three BMI subgroups. A Chi-square test or Fisher's exact test was used to evaluate categorical variables in the three BMI subgroups. PFS was the date of the initiation of first-line treatment to disease progression or death, censoring at the date of the last follow-up without disease progression. OS was the date of diagnosis to that of death, censoring at the date of the last follow-up in alive patients. The Kaplan-Meier estimate and the log-rank test were used to evaluate the PFS and OS. A $p$ value of $<0.05$ was considered statistically significant.

\section{Results}

\subsection{Patient Characteristics}

A total of 513 advanced NSCLC patients who were tested for EGFR mutation status were included in the final study out of 1510 lung cancer patients (Figure 1). The EGFR mutation was found in $54.9 \%(n=282)$ of the patients. All NSCLC patients with EGFR mutations received first-line EGFR-TKIs, while 211 out of 231 patients without EGFR mutations received chemotherapy. The median duration between follow-ups was 33.0 months, while the longest time between follow-ups was 54.8 months. After the follow-up period, $22.8 \%$ of the patients $(117 / 513)$ were still alive. PFS and OS were 7.0 and 14.4 months, respectively, in all patients, 3.6 and 8.4 months in patients with wild-type EGFR, respectively, and 10.9 and 21.0 months in patients with EGFR mutation, respectively. Table 1 displays the baseline clinical characteristics of all of the patients.

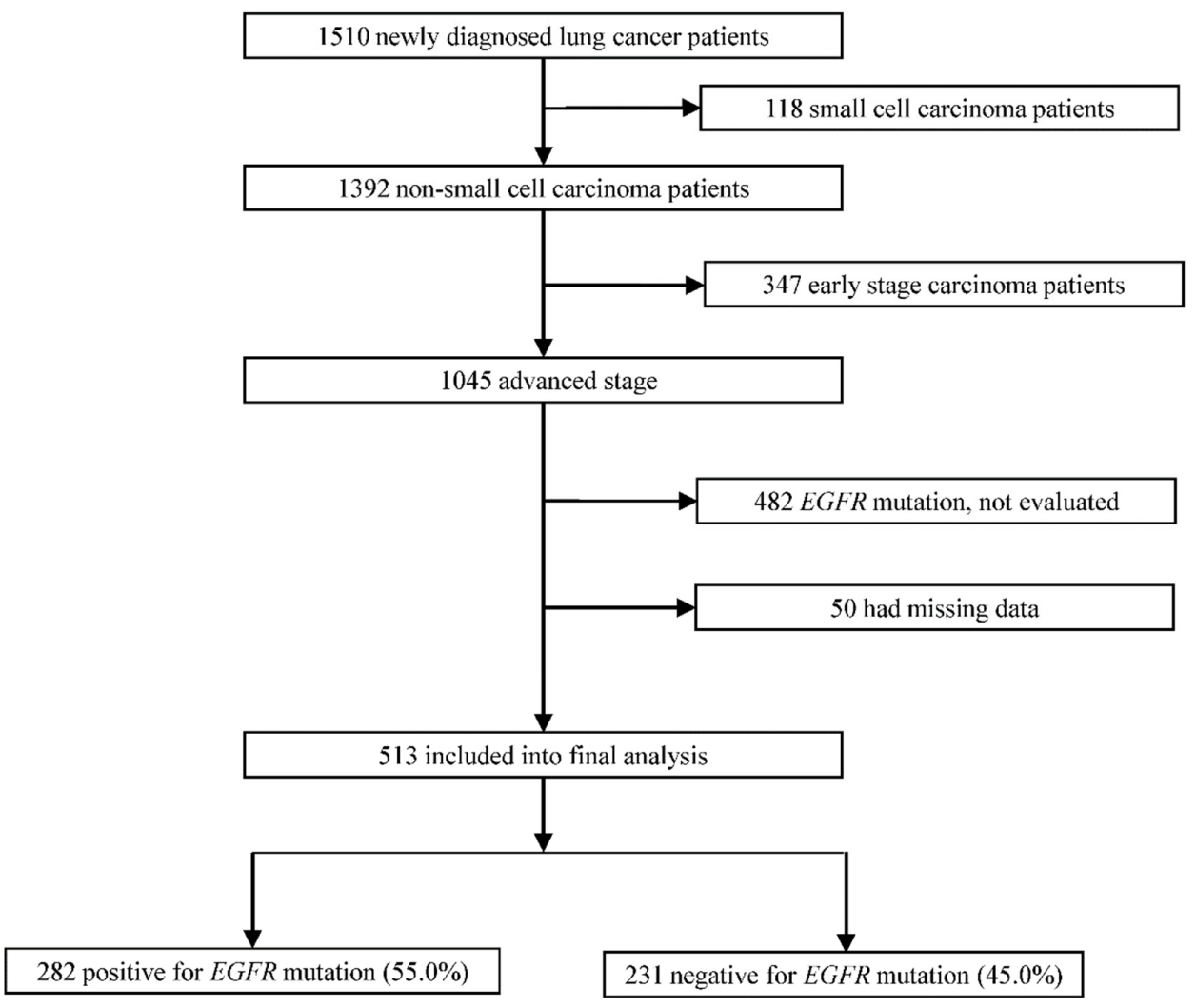

Figure 1. The flow diagram depicting the patient's enrollment scheme. 
Table 1. Clinical characteristics of study patients $(n=513)$.

\begin{tabular}{|c|c|c|c|c|}
\hline & All Patients $(n=513)$ & EGFR Wild Type $(n=231)$ & EGFR Mutant $(n=282)$ & $p$ Value \\
\hline Age (mean \pm SD) & $63.7 \pm 12.3$ & $63.0 \pm 12.2$ & $64.2 \pm 12.3$ & 0.249 \\
\hline $\mathrm{BMI}($ mean $\pm \mathrm{SD})$ & $23.0 \pm 3.6$ & $22.6 \pm 3.6$ & $23.3 \pm 3.7$ & 0.022 \\
\hline Sex & & & & $<0.001$ \\
\hline Male & $256(49.9)$ & $135(58.4)$ & $121(42.9)$ & \\
\hline Female & $257(50.1)$ & $96(41.6)$ & $161(57.1)$ & \\
\hline $\mathrm{DM}$ & $55(10.7)$ & $43(18.6)$ & $12(4.3)$ & $<0.001$ \\
\hline COPD & $41(8.0)$ & $27(11.7)$ & $14(5.0)$ & 0.005 \\
\hline Smoking history & & & & 0.001 \\
\hline Never & $319(62.2)$ & $125(54.1)$ & $194(68.8)$ & \\
\hline Former/current & $194(37.8)$ & $106(45.9)$ & $88(31.2)$ & \\
\hline Performance status & & & & 0.499 \\
\hline ECOG 0-2 & $471(91.8)$ & $210(90.9)$ & $261(92.6)$ & \\
\hline ECOG 3-4 & $42(8.2)$ & $21(9.1)$ & $21(7.4)$ & \\
\hline Stage & & & & 0.584 \\
\hline IIB & $60(11.7)$ & $29(12.6)$ & $31(11.0)$ & \\
\hline IV & $453(88.3)$ & $202(87.4)$ & $251(89.0)$ & \\
\hline Tumor type & & & & $<0.001$ \\
\hline Adenocarcinoma & $435(84.8)$ & $176(76.2)$ & $259(91.8)$ & \\
\hline Non-adenocarcinoma & $78(15.2)$ & $55(23.8)$ & $23(8.2)$ & \\
\hline Brain metastases & $116(22.6)$ & $53(22.9)$ & $63(22.3)$ & 0.871 \\
\hline Bone metastases & $226(44.1)$ & $107(46.3)$ & $119(42.2)$ & 0.349 \\
\hline Liver metastases & 70 (13.6) & $35(15.2)$ & $35(12.4)$ & 0.368 \\
\hline Pleura metastases & $185(36.1)$ & $76(32.9)$ & $109(38.7)$ & 0.177 \\
\hline No. of distal metastasis & $1.5 \pm 1.1$ & $1.6 \pm 1.1$ & $1.4 \pm 1.0$ & 0.041 \\
\hline
\end{tabular}

Abbreviations: BMI, body mass index; COPD, chronic obstructive pulmonary disease; DM, diabetes mellitus; ECOG, eastern cooperative oncology group; EGFR, epidermal growth factor receptor.

\subsection{Clinical Characteristics between NSCLC Patients with Wild Type and Mutant EGFR}

When comparing the baseline clinical characteristics in patients with the wild type and mutant EGFR, there were significant differences in BMI (patients with wild type vs. mutant EGFR: $22.6 \pm 3.6$ vs. $23.3 \pm 3.7, p=0.022$ ), sex (wild type vs. mutant EGFR: $41.6 \%$ women vs. $57.1 \%, p<0.001$ ), DM (wild type vs. mutant EGFR: 18.6 vs. $4.3 \%, p<0.001$ ), COPD (wild type vs. mutant EGFR: 11.7 vs. $5.0 \%, p=0.005$ ), smoking history (wild type vs. mutant EGFR: $45.9 \%$ vs. $31.2 \%, p=0.001$ ), tumors of adenocarcinoma histology (wild type vs. mutant EGFR: $76.2 \%$ vs. $91.8 \%, p<0.001$ ), and the number of distal metastasis (wild type vs. mutant EGFR: $1.6 \pm 1.1$ vs. $1.4 \pm 1.0, p=0.041$ ) (Table 1). There were no significant differences in the age, ECOG PS, tumor stage, or sites of distant metastases including brain, bone, liver, and pleura between patients with the wild type and mutant EGFR (Table 1).

\subsection{Clinical Characteristics of Underweight, Normal-Weight, and Overweight Patients}

Underweight NSCLC patients were more likely to have COPD $(p=0.019)$ (Table 2). In the subgroup analyses, underweight lung cancer patients were older in those with wild type EGFR (Table 2). More COPD, poor ECOG PS, and more liver metastases in underweight lung cancer were only noted in EGFR mutant patients (Table 2). Normalweight patients were more likely to have never been a smoker in EGFR mutant patients, but not in EGFR wild-type patients. (Table 2) Other baseline parameters did not differ statistically between underweight, normal-weight, and overweight patients (Table 2). 
Table 2. Clinical characteristics of underweight, normal weight, and overweight patients.

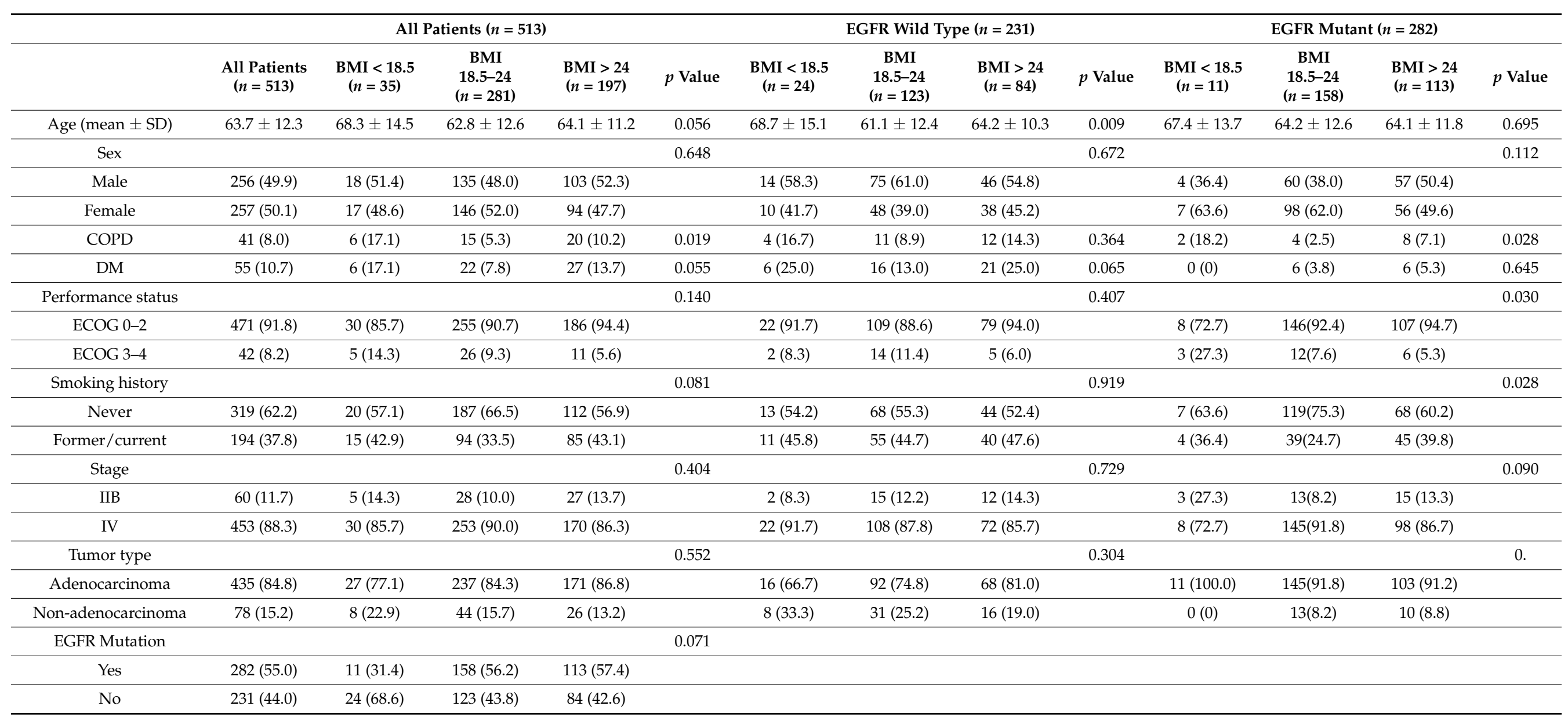


Table 2. Cont

\begin{tabular}{|c|c|c|c|c|c|c|c|c|c|c|c|c|c|}
\hline & \multicolumn{5}{|c|}{ All Patients $(n=513)$} & \multicolumn{4}{|c|}{ EGFR Wild Type $(n=231)$} & \multicolumn{4}{|c|}{ EGFR Mutant $(n=282)$} \\
\hline & $\begin{array}{l}\text { All Patients } \\
\quad(n=513)\end{array}$ & $\begin{array}{c}\text { BMI }<18.5 \\
(n=35)\end{array}$ & $\begin{array}{c}\text { BMI } \\
18.5-24 \\
(n=281)\end{array}$ & $\begin{array}{c}\text { BMI > 24 } \\
(n=197)\end{array}$ & $p$ Value & $\begin{array}{c}\text { BMI }<18.5 \\
(n=24)\end{array}$ & $\begin{array}{c}\text { BMI } \\
18.5-24 \\
(n=123)\end{array}$ & $\begin{array}{c}\text { BMI > 24 } \\
(n=84)\end{array}$ & $p$ Value & $\begin{array}{c}\text { BMI }<18.5 \\
\quad(n=11)\end{array}$ & $\begin{array}{c}\text { BMI } \\
18.5-24 \\
(n=158)\end{array}$ & $\begin{array}{c}\mathrm{BMI}>24 \\
(n=113)\end{array}$ & $p$ Value \\
\hline EGFR Mutation type & & & & & & & & & & & & & 0.985 \\
\hline Common & & & & & & & & & & $10(90.9)$ & $141(89.2)$ & $101(89.4)$ & \\
\hline Uncommon & & & & & & & & & & $1(9.1)$ & $17(10.8)$ & $12(10.6)$ & \\
\hline Brain metastases & $116(22.6)$ & $7(35.0)$ & $50(28.6)$ & $61(20.3)$ & 0.391 & $5(20.8)$ & $33(26.8)$ & $15(17.9)$ & 0.310 & $2(18.2)$ & $37(23.4)$ & $24(21.2)$ & 0.863 \\
\hline Liver metastases & 70 (13.6) & $4(20.0)$ & 29 (16.6) & $36(12.0)$ & 0.525 & $4(16.7)$ & $13(10.6)$ & $18(21.4)$ & 0.099 & $3(27.3)$ & $24(15.2)$ & $8(7.1)$ & 0.043 \\
\hline Pleura metastases & $185(36.1)$ & $11(55.0)$ & $58(33.1)$ & $108(36.0)$ & 0.467 & $13(54.2)$ & $34(27.6)$ & $29(34.5)$ & 0.038 & $3(27.3)$ & $65(41.1)$ & $41(36.3)$ & 0.527 \\
\hline No. of distal metastasis & $1.5 \pm 1.1$ & $1.9 \pm 1.2$ & $1.5 \pm 1.0$ & $1.5 \pm 1.1$ & 0.064 & $2.0 \pm 1.2$ & $1.6 \pm 1.1$ & $1.6 \pm 1.2$ & 0.274 & $1.7 \pm 1.4$ & $1.5 \pm 0.9$ & $1.4 \pm 1.0$ & 0.292 \\
\hline
\end{tabular}

Abbreviations: BMI, body mass index; COPD, chronic obstructive pulmonary disease; DM, diabetes mellitus; ECOG, eastern cooperative oncology group; EGFR, epidermal growth factor receptor. 


\subsection{Influence of Baseline BMI on Outcomes of NSCLC Patients with or without EGFR Mutation}

Overweight patients exhibited a longer PFS than the underweight patients (8.2 vs. 3.2 months, $p<0.001$ ) across all advanced NSCLC patients. (See Figure 2A.) There was no statistical significant difference in PFS between the patients who were overweight and those who were normal-weight. Overweight people lived longer than the normal-weight and underweight people. (16.7 months vs. 14.9 months, $p=0.047$; and 14.9 months vs. 5.6 months, $p$ 0.001, respectively) (Figure 2B). Patients who were a normal weight had a longer PFS (6.8 vs. 3.2 months, $p<0.001)$ and OS (14.9 months vs. 5.6 months, $p=0.007)$ than those who were underweight.
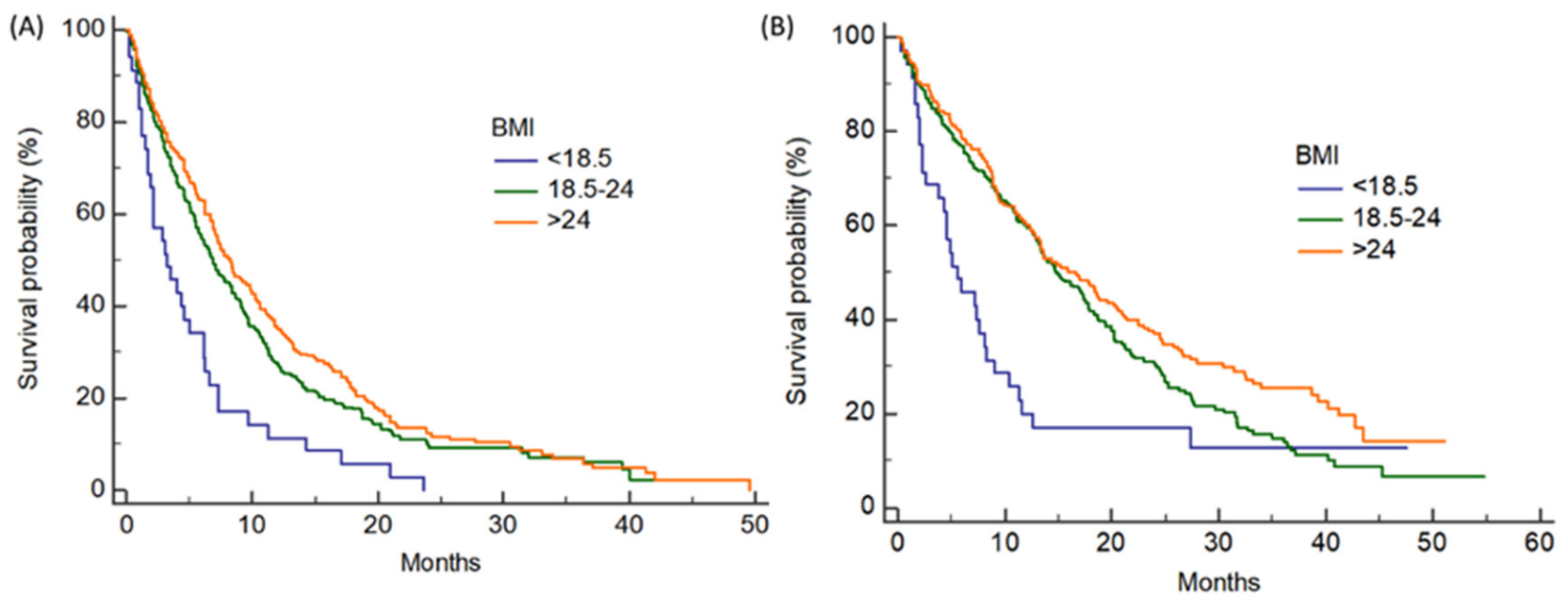

$\left.\begin{array}{lcc}\text { All patients } & \mathrm{n} & \mathrm{PFS}(\mathrm{mo}) \\ \hline<18.5 & 35 & 3.2 \\ 18.5-24 & 270 & 6.8 \\ >24 & 188 & 8.2\end{array}\right\}{ }^{* *}$

$\left.\begin{array}{lll}\text { All patients } & \mathrm{n} & \mathrm{OS}(\mathrm{mo}) \\ \hline<18.5 & 35 & 5.6 \\ 18.5-24 & 281 & 14.9\{* * \\ >24 & 197 & 16.7\end{array}\right\} * * * *$

Figure 2. Influence of the baseline BMI on (A) PFS and (B) OS of NSCLC patients. BMI—body mass index; PFS—progressionfree survival; OS—overall survival; NSCLC—non-small cell lung cancer; Note: ${ }^{*} p<0.05,{ }^{* *} p<0.001$.

\subsection{Influence of Baseline BMI on Outcomes of NSCLC Patients with Wild-Type EGFR Status}

Overweight NSCLC patients with the wild-type EGFR status exhibited longer PFS and OS than the underweight patients (4.6 vs. 2.1 months, $p=0.003 ; 8.9$ vs. 4.3 months, $p=0.003$, respectively) (Figure 3A,B) Patients who were a normal weight had a longer PFS and OS than those who were underweight ( 3.5 vs. 2.1 months, $p=0.018 ; 8.8$ vs. 4.3 months, $p=0.003$, respectively) (Figure 3A). There was no statistically significant difference in the PFS or OS between patients who were overweight or normal-weight.

\subsection{Influence of Baseline BMI on Outcomes of NSCLC Patients with EGFR Mutation}

There was no difference in PFS between overweight, normal-weight, and underweight patients among the EGFR mutant patients (Figure 4A). The overweight patients with EGFR mutations, on the other hand, had a higher life expectancy than the normal-weight patients. ( $p=0.025,23.0$ vs. 20.2 months) (See Figure 4B.) 

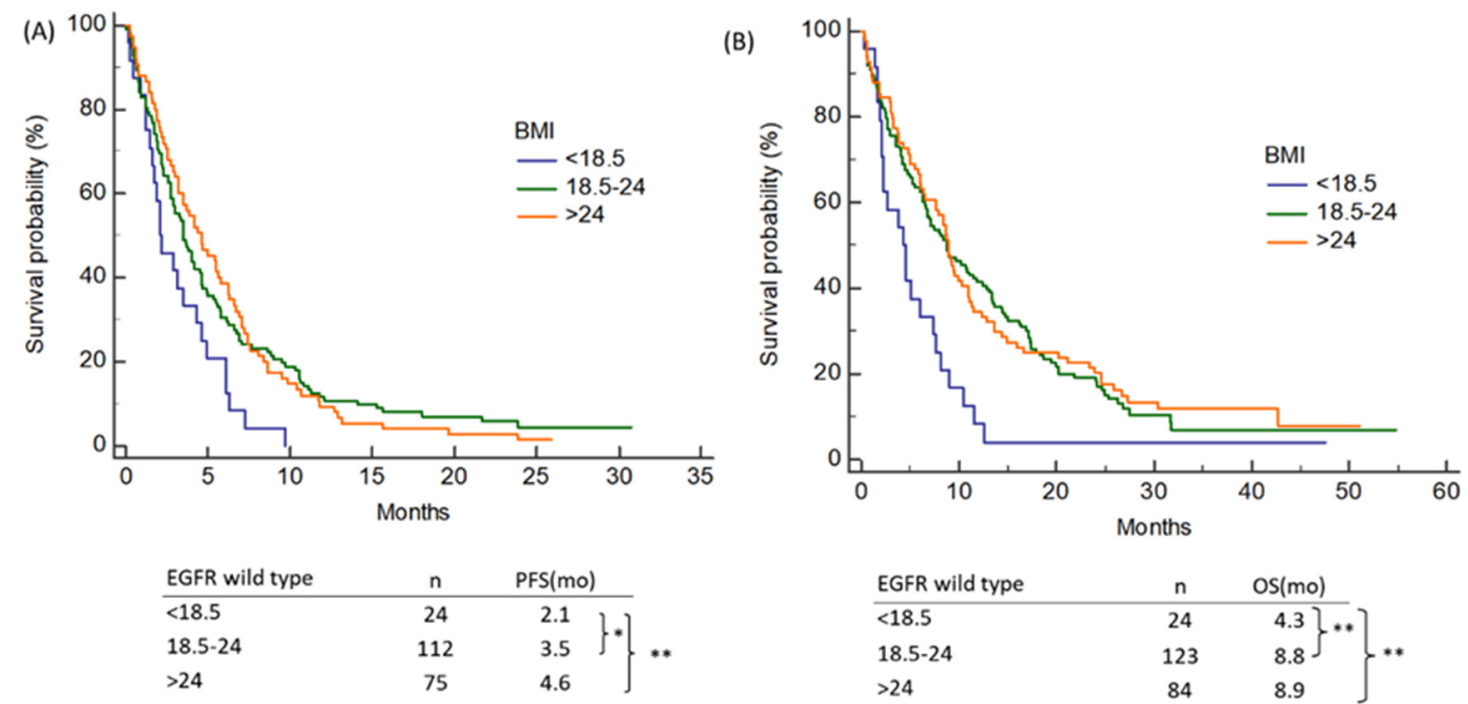

Figure 3. Influence of the baseline BMI on (A) PFS and (B) OS of NSCLC patients with wild-type EGFR status. BMI-body mass index; PFS—-progression-free survival; OS—overall survival; NSCLC—non-small cell lung cancer; EGFR—epidermal growth factor receptor; Note: ${ }^{*} p<0.05,{ }^{* *} p<0.001$.

(A)

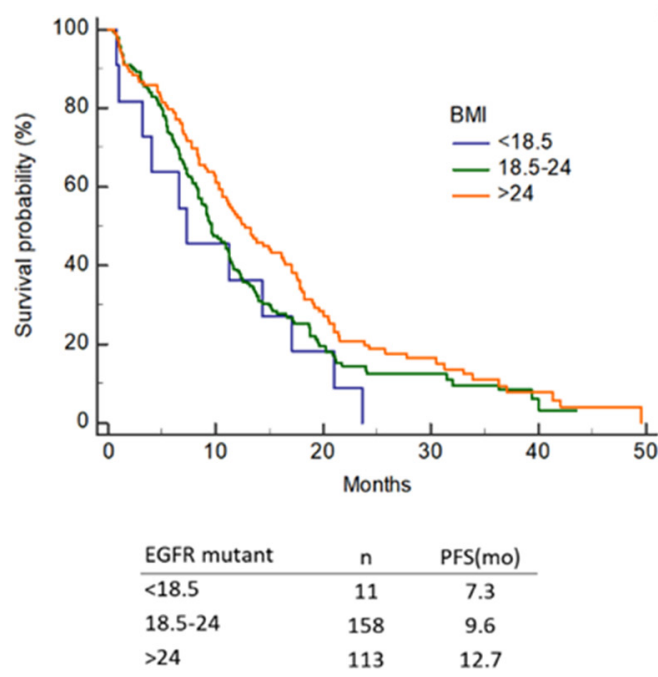

(B)

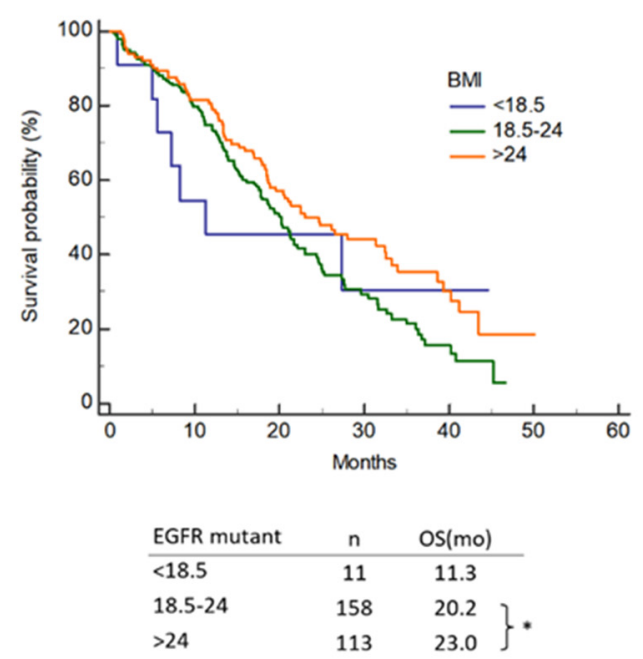

Figure 4. Influence of the baseline BMI on (A) PFS and (B) OS of NSCLC patients with EGFR mutation. BMI-body mass index; PFS—progression-free survival; OS—overall survival; NSCLC—non-small cell lung cancer; EGFR—epidermal growth factor receptor; Note: ${ }^{*} p<0.05$.

\subsection{Influence of Weight Loss on Outcomes of NSCLC Patients}

Among the 513 patients with available baseline BMI data, 364 had follow-up BMI data within 3 months of a lung cancer diagnosis. A total of $264(58.5 \%)$ of the 364 patients lost weight. NSCLC patients with wild-type EGFR were more likely to lose bodyweight than NSCLC patients with mutant EGFR (116/166 [69.9\%] vs. 97/198 [49.0\%], respectively, $p<0.0001)$. A reduction in bodyweight was linked with shorter OS in both patients with mutant EGFR (17.1 vs. 30.5 months, $p<0.001)$ and patients with wild-type EGFR (7.8 vs. 18.7 months, $p<0.001$ ). (Figure 5) 
(A)
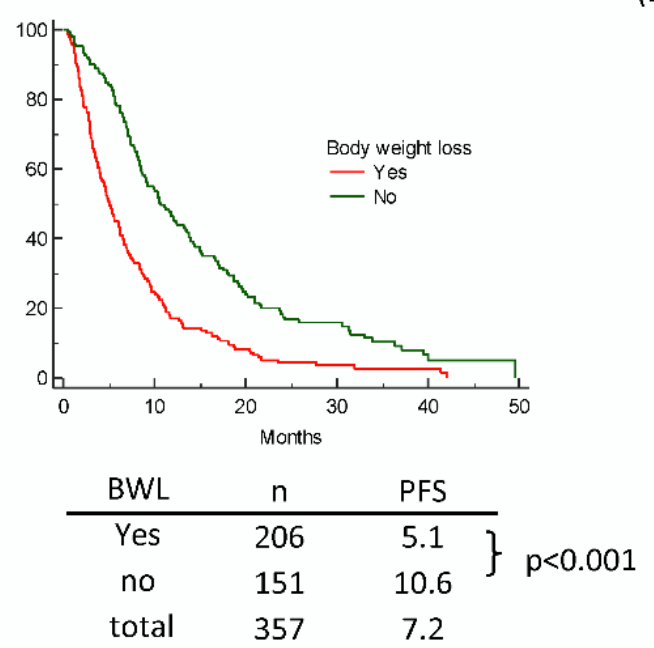

(C)
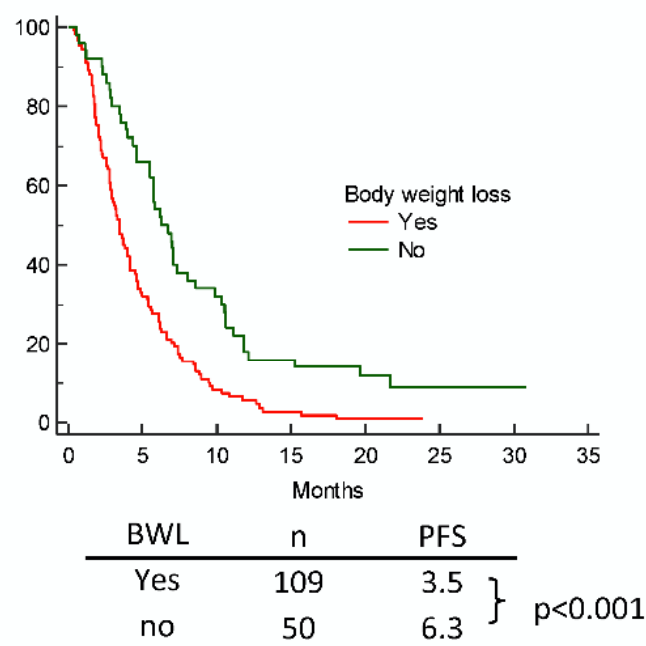

(E)

total $\quad 159 \quad 4.1$

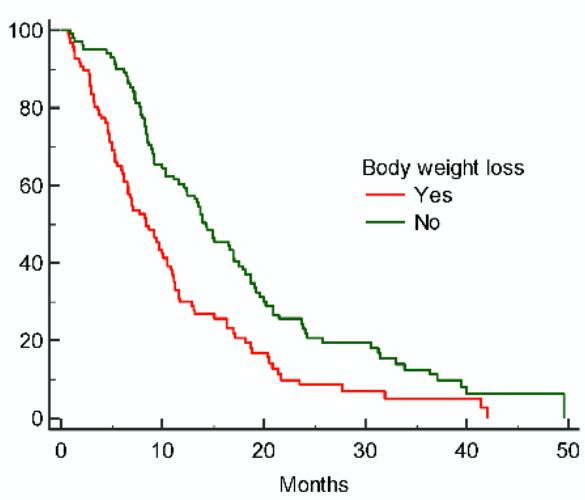

\begin{tabular}{ccc} 
BWL & $\mathrm{n}$ & $\mathrm{PFS}$ \\
\hline Yes & 97 & 8.4 \\
no & 101 & 14.3 \\
total & 198 & 10.9
\end{tabular}

(B)

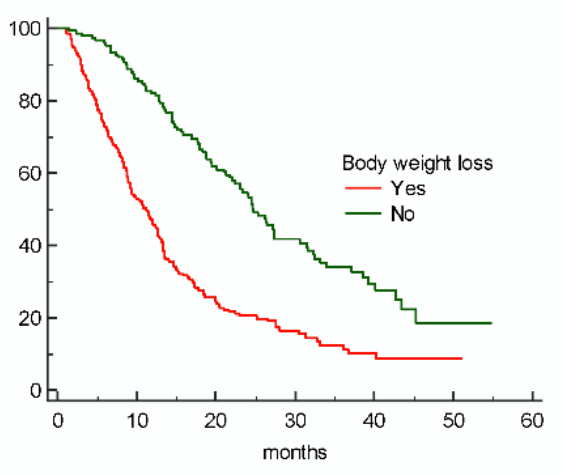

\begin{tabular}{|c|c|c|c|}
\hline BWL & $\mathrm{n}$ & OS & \\
\hline Yes & 213 & 11.2 & \\
\hline no & 151 & $24.6\}$ & $p<0.001$ \\
\hline total & 364 & 14.9 & \\
\hline
\end{tabular}

(D)
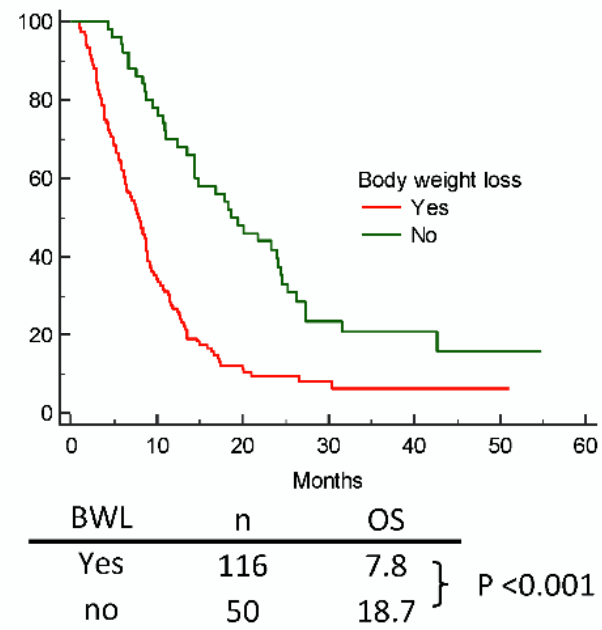

(F)

total $\quad 166 \quad 9.3$

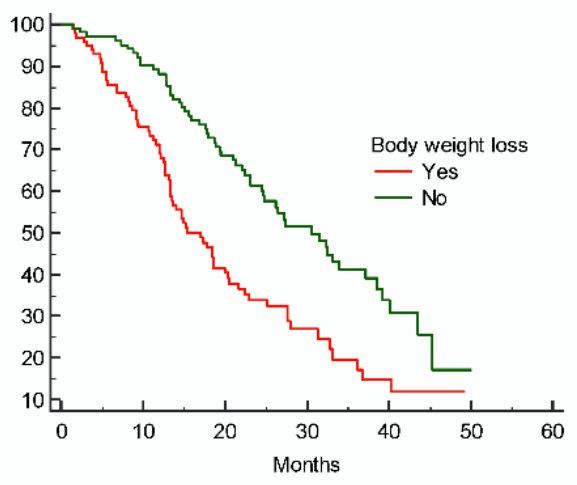

\begin{tabular}{|c|c|c|c|}
\hline BWL & $n$ & OS & \\
\hline Yes & 97 & 17.12 & \\
\hline no & 101 & $30.5^{\}}$ & $p<0.001$ \\
\hline total & 198 & 22.5 & \\
\hline
\end{tabular}

Figure 5. Influence of the body weight loss on (A) PFS and (B) OS of all NSCLC patients; (C) PFS, and (D) OS of NSCLC patients with wild-type EGFR status; (E) PFS and (F) OS of NSCLC patients with EGFR mutation. BMI-body mass index; PFSprogression-free survival; OS — overall survival; NSCLC—-non-small cell lung cancer; EGFR—epidermal growth factor receptor. 


\section{Discussion}

Our research found that patients with EGFR mutations who were overweight had a higher chance of survival. Previous research on the relationship between baseline BMI and survival in patients that were receiving EGFR-TKIs yielded contradictory results. A lower BMI was related to a worse survival result in one study [16], which was consistent with our findings. Another study with a small number of patients found that having a higher BMI was linked with shorter PFS [15]. The author hypothesized that the outcome was due to greater EGFR-TKI blood concentrations in the smaller body size group. In a randomized dosage escalation study with gefitinib, however, the higher dose group had higher mean plasma concentrations but the same response rate and survival outcomes [24].

A higher BMI was observed to be related to a better prognosis in NSCLC patients who were undergoing chemotherapies, which was consistent with prior research. [7-9]. Surprisingly, one of these studies stated that the protective benefit of a high BMI is only temporary [7]. An obese patients' risk of all-cause death increased substantially once they lived for more than 16 months [7]. Our research also found that overweight patients who lived for more than 18 months had a higher death rate. Several ideas have been advanced, including the possibility of a synergy between the peroxisome proliferatoractivated receptor (PPAR) ligands and platinum-based medicines in first-line treatment [25] Rapid progression following the absence of platinum-based agents in subsequent lines of therapy were due to a decrease in the synergy between platinum-based agents and PPAR ligands. Another theory was that overweight individuals were more likely to be given anti-diabetic medications [26]. Interactions with anti-diabetic medications may have contributed to their improved prognosis in their early cancer treatment course [27].

Our research found that a bodyweight reduction was linked with shorter OS in both patients with mutant EGFR (17.1 vs. 30.5 months, $p<0.001)$ and those with wild-type EGFR (7.8 vs. 18.7 months, $p<0.001)$. When comparing the NSCLC patients with the wild-type EGFR to those with mutant EGFR, our study found that individuals with the wild-type EGFR were more likely to experience early bodyweight loss. Previous research has indicated that cancer patients who lose weight have a worse prognosis than those who do not [28-30]. Pre-diagnosed weight reduction was found to be a better predictor of survival in lung cancer patients [31]. In recent research [32], weight loss during definitive radiotherapy was observed to result in a worse OS rate in patients with locally advanced NSCLC. Previous research found that a weight reduction at presentation had a negative influence on the survival outcomes in patients with EGFR-mutant advanced NSCLC that was treated with first-line EGFR-TKI [33]. Weight loss, independent of EGFR mutation status, was linked with a poor outcome in our research. Several weight loss theories have been proposed, including but not limited to systemic inflammation and the microbiotamuscle axis [34-36]. Several treatments enhanced the quality of life in cancer patients with anorexia or cachexia [37-39]. In cancer cachexia, oral nutritional interventions such as megestrol acetate and anamorelin enhanced the quality of life [39]. Some treatments, such as humanized monoclonal antibodies targeting human IL-6, histone deacetylase inhibitors, and Toll-like receptor agonists, showed promise in preclinical and clinical trials [40-43]. There were also some complementary medicines that were used for anorexia and cachexia in cancer patients, such as herbal medicine and acupuncture [37,44,45]. However, none of the existing cancer anorexia and cachexia treatment methods enhanced survival. [35,38,43,46]. Novel approaches are being advocated to combat cancer-related weight loss and consequent cancer cachexia-related death.

There were some limitations to our investigation. This retrospective analysis did not include other nutritional evaluations or comprehensive information regarding nutritional intervention [47-50]. In a future study, we will focus on dietary intervention and weight loss prevention. 


\title{
5. Conclusions
}

NSCLC patients at advanced stages with a lower BMI and early weight loss had a worse outcome independent of EGFR mutation status.

\begin{abstract}
Author Contributions: Conceptualization, Y.-M.C., C.-H.L., C.-C.T., T.-Y.C., and M.-C.L.; Data curation, C.-Y.L., Y.-H.T., H.-C.C. (Hung-Chen Chen), H.-C.C. (Huang-Chih Chang), K.-T.H., Y.-C.C. (Yung-Che Chen), and W.-F.F.; Formal analysis, Y.-C.C. (Ya-Chun Chang), C.-C.T., K.-T.H., and W.F.F.; Funding acquisition, H.-C.C. (Hung-Chen Chen), H.-C.C. (Huang-Chih Chang), and Y.-C.C.; Resources, C.-C.W.; Writing-original draft, Y.-M.C.; Writing-review \& editing, M.-C.L. All authors have read and agreed to the published version of the manuscript.
\end{abstract}

Funding: This research received no external funding.

Institutional Review Board Statement: The study was authorized by the Kaohsiung Chang Gung Memorial Hospital's Institutional Review Board, with permission number 104-7011C.

Informed Consent Statement: Patient consent was waived due to retrospective designed study.

Data Availability Statement: Data supporting reported results can be found at https://1drv.ms/u/ s!AsRf0H3OWdB9gbIVN2v1yVO1US4kNw? $=$ iU6Zzf (accessed on 23 October 2021).

Acknowledgments: We would like to thank the Biostatistics Center, Kaohsiung Chang Gung Memorial Hospital for the statistics consultation.

Conflicts of Interest: The authors declare no conflict of interest.

\section{References}

1. Bray, F.; Ferlay, J.; Soerjomataram, I.; Siegel, R.L.; Torre, L.A.; Jemal, A. Global cancer statistics 2018: GLOBOCAN estimates of incidence and mortality worldwide for 36 cancers in 185 countries. CA Cancer J. Clin. 2018, 68, 394-424. [CrossRef] [PubMed]

2. Calle, E.E.; Kaaks, R. Overweight, obesity and cancer: Epidemiological evidence and proposed mechanisms. Nat. Rev. Cancer 2004, 4, 579-591. [CrossRef]

3. Renehan, A.G.; Soerjomataram, I.; Leitzmann, M.F. Interpreting the epidemiological evidence linking obesity and cancer: A framework for population-attributable risk estimations in Europe. Eur. J. Cancer 2010, 46, 2581-2592. [CrossRef]

4. $\quad$ Bhaskaran, K.; Douglas, I.; Forbes, H.; dos-Santos-Silva, I.; Leon, D.A.; Smeeth, L. Body-mass index and risk of 22 specific cancers: A population-based cohort study of 5.24 million UK adults. Lancet 2014, 384, 755-765. [CrossRef]

5. Renehan, A.G.; Tyson, M.; Egger, M.; Heller, R.F.; Zwahlen, M. Body-mass index and incidence of cancer: A systematic review and meta-analysis of prospective observational studies. Lancet 2008, 371, 569-578. [CrossRef]

6. Matsunaga, T.; Suzuki, K.; Imashimizu, K.; Banno, T.; Takamochi, K.; Oh, S. Body Mass Index as a Prognostic Factor in Resected Lung Cancer: Obesity or Underweight, Which Is the Risk Factor? Thorac. Cardiovasc. Surg. 2015, 63, 551-557. [CrossRef]

7. Dahlberg, S.E.; Schiller, J.H.; Bonomi, P.B.; Sandler, A.B.; Brahmer, J.R.; Ramalingam, S.S.; Johnson, D.H. Body mass index and its association with clinical outcomes for advanced non-small-cell lung cancer patients enrolled on Eastern Cooperative Oncology Group clinical trials. J. Thorac. Oncol. 2013, 8, 1121-1127. [CrossRef]

8. Rivera, C.; Pecuchet, N.; Wermert, D.; Pricopi, C.; Le Pimpec-Barthes, F.; Riquet, M.; Fabre, E. Obesity and lung cancer: Incidence and repercussions on epidemiology, pathology and treatments. Rev. Pneumol. Clin. 2015, 71, 37-43. [CrossRef]

9. Leung, C.C.; Lam, T.H.; Yew, W.W.; Chan, W.M.; Law, W.S.; Tam, C.M. Lower lung cancer mortality in obesity. Int. J. Epidemiol. 2011, 40, 174-182. [CrossRef] [PubMed]

10. Ettinger, D.S.; Wood, D.E.; Aisner, D.L.; Akerley, W.; Bauman, J.R.; Bharat, A.; Bruno, D.S.; Chang, J.Y.; Chirieac, L.R.; D’Amico, T.A.; et al. NCCN Guidelines insights: Non-Small Cell Lung Cancer, Version 2.2021. J. Natl. Compr. Cancer Netw. 2021, 19, 254-266. [CrossRef]

11. Chen, G.; Feng, J.; Zhou, C.; Wu, Y.L.; Liu, X.Q.; Wang, C.; Zhang, S.; Wang, J.; Zhou, S.; Ren, S.; et al. Quality of life (QoL) analyses from OPTIMAL (CTONG-0802), a phase III, randomised, open-label study of first-line erlotinib versus chemotherapy in patients with advanced EGFR mutation-positive non-small-cell lung cancer (NSCLC). Ann. Oncol. 2013, 24, 1615-1622. [CrossRef] [PubMed]

12. Thongprasert, S.; Duffield, E.; Saijo, N.; Wu, Y.L.; Yang, J.C.; Chu, D.T.; Liao, M.; Chen, Y.M.; Kuo, H.P.; Negoro, S.; et al. Health-related quality-of-life in a randomized phase III first-line study of gefitinib versus carboplatin/paclitaxel in clinically selected patients from Asia with advanced NSCLC (IPASS). J. Thorac. Oncology 2011, 6, 1872-1880. [CrossRef] [PubMed]

13. Yang, J.C.; Wu, Y.L.; Schuler, M.; Sebastian, M.; Popat, S.; Yamamoto, N.; Zhou, C.; Hu, C.P.; O’Byrne, K.; Feng, J.; et al. Afatinib versus cisplatin-based chemotherapy for EGFR mutation-positive lung adenocarcinoma (LUX-Lung 3 and LUX-Lung 6): Analysis of overall survival data from two randomised, phase 3 trials. Lancet Oncol. 2015, 16, 141-151. [CrossRef] 
14. Chen, Y.M.; Lai, C.H.; Chang, H.C.; Chao, T.Y.; Tseng, C.C.; Fang, W.F.; Wang, C.C.; Chung, Y.H.; Wang, Y.H.; Su, M.C.; et al. The impact of clinical parameters on progression-free survival of non-small cell lung cancer patients harboring EGFR-mutations receiving first-line EGFR-tyrosine kinase inhibitors. Lung Cancer 2016, 93, 47-54. [CrossRef] [PubMed]

15. Sun, H.; Sun, X.; Zhai, X.; Guo, J.; Liu, Y.; Ying, J.; Wang, Z. Body mass index and exon 19 mutation as factors predicting the therapeutic efficacy of gefitinib in patients with epidermal growth factor receptor mutation-positive non-small cell lung cancer. Thorac. Cancer 2016, 7, 61-65. [CrossRef]

16. Boker, B.; Luders, H.; Grohe, C. Prognostic relevance of body mass index and rash for patients with metastatic non-small-cell lung cancer under therapy with erlotinib. Pneumologie 2012, 66, 89-95. [CrossRef] [PubMed]

17. Imai, H.; Kuwako, T.; Kaira, K.; Masuda, T.; Miura, Y.; Seki, K.; Sakurai, R.; Utsugi, M.; Shimizu, K.; Sunaga, N.; et al. Evaluation of gefitinib efficacy according to body mass index, body surface area, and body weight in patients with EGFR-mutated advanced non-small cell lung cancer. Cancer Chemother. Pharmacol. 2017, 79, 497-505. [CrossRef]

18. Consultation, W.H.O.E. Appropriate body-mass index for Asian populations and its implications for policy and intervention strategies. Lancet 2004, 363, 157-163. [CrossRef]

19. Deurenberg-Yap, M.; Schmidt, G.; van Staveren, W.A.; Deurenberg, P. The paradox of low body mass index and high body fat percentage among Chinese, Malays and Indians in Singapore. Int. J. Obes. Relat. Metab. Disord. 2000, 24, 1011-1017. [CrossRef]

20. Deurenberg, P.; Yap, M.; van Staveren, W.A. Body mass index and percent body fat: A meta analysis among different ethnic groups. Int. J. Obes. Relat. Metab. Disord. 1998, 22, 1164-1171. [CrossRef]

21. Thivat, E.; Therondel, S.; Lapirot, O.; Abrial, C.; Gimbergues, P.; Gadea, E.; Planchat, E.; Kwiatkowski, F.; Mouret-Reynier, M.A.; Chollet, P.; et al. Weight change during chemotherapy changes the prognosis in non metastatic breast cancer for the worse. BMC cancer 2010, 10, 648. [CrossRef] [PubMed]

22. Chen, Y.M.; Lai, C.H.; Chang, H.C.; Chao, T.Y.; Tseng, C.C.; Fang, W.F.; Wang, C.C.; Chung, Y.H.; Wang, Y.H.; Su, M.C.; et al. Baseline and trend of lymphocyte-to-monocyte ratio as prognostic factors in epidermal growth factor receptor mutant non-small cell lung cancer patients treated with first-line epidermal growth factor receptor tyrosine kinase inhibitors. PLoS ONE 2015, 10, e0136252. [CrossRef] [PubMed]

23. Eisenhauer, E.A.; Therasse, P.; Bogaerts, J.; Schwartz, L.H.; Sargent, D.; Ford, R.; Dancey, J.; Arbuck, S.; Gwyther, S.; Mooney, M.; et al. New response evaluation criteria in solid tumours: Revised RECIST guideline (version 1.1). Eur. J. Cancer 2009, 45, 228-247. [CrossRef]

24. Xue, C.; Hong, S.; Li, N.; Feng, W.; Jia, J.; Peng, J.; Lin, D.; Cao, X.; Wang, S.; Zhang, W.; et al. Randomized, Multicenter Study of gefitinib dose-escalation in advanced non-small-cell lung cancer patients achieved stable disease after one-month gefitinib treatment. Sci. Rep. 2015, 5, 10648. [CrossRef] [PubMed]

25. Girnun, G.D.; Naseri, E.; Vafai, S.B.; Qu, L.; Szwaya, J.D.; Bronson, R.; Alberta, J.A.; Spiegelman, B.M. Synergy between PPARgamma ligands and platinum-based drugs in cancer. Cancer Cell 2007, 11, 395-406. [CrossRef]

26. Shackelford, D.B.; Abt, E.; Gerken, L.; Vasquez, D.S.; Seki, A.; Leblanc, M.; Wei, L.; Fishbein, M.C.; Czernin, J.; Mischel, P.S.; et al. LKB1 inactivation dictates therapeutic response of non-small cell lung cancer to the metabolism drug phenformin. Cancer Cell 2013, 23, 143-158. [CrossRef]

27. Wu, N.; Gu, C.; Gu, H.; Hu, H.; Han, Y.; Li, Q. Metformin induces apoptosis of lung cancer cells through activating JNK/p38 MAPK pathway and GADD153. Neoplasma 2011, 58, 482-490. [CrossRef]

28. Zeng, Q.; Shen, L.J.; Guo, X.; Guo, X.M.; Qian, C.N.; Wu, P.H. Critical weight loss predicts poor prognosis in nasopharyngeal carcinoma. BMC Cancer 2016, 16, 169. [CrossRef]

29. Adenis, A.; Tresch, E.; Dewas, S.; Romano, O.; Messager, M.; Amela, E.; Clisant, S.; Kramar, A.; Mariette, C.; Mirabel, X. Clinical complete responders to definite chemoradiation or radiation therapy for oesophageal cancer: Predictors of outcome. BMC Cancer 2013, 13, 413. [CrossRef]

30. Tougeron, D.; Hamidou, H.; Scotte, M.; Di Fiore, F.; Antonietti, M.; Paillot, B.; Michel, P. Esophageal cancer in the elderly: An analysis of the factors associated with treatment decisions and outcomes. BMC Cancer 2010, 10, 510. [CrossRef]

31. Morel, H.; Raynard, B.; d'Arlhac, M.; Hauss, P.A.; Lecuyer, E.; Oliviero, G.; Marty, C.; Gury, J.P.; Asselain, B.; Grivaux, M.; et al. Prediagnosis weight loss, a stronger factor than BMI, to predict survival in patients with lung cancer. Lung Cancer 2018, 126, 55-63. [CrossRef]

32. Kim, Y.J.; Song, C.; Eom, K.Y.; Kim, I.A.; Kim, J.S. Combined Chemoradiotherapy-induced Weight Loss Decreases Survival in Locally Advanced Non-small Cell Lung Cancer Patients. In Vivo 2019, 33, 955-961. [CrossRef] [PubMed]

33. Lin, L.; Zhao, J.; Hu, J.; Huang, F.; Han, J.; He, Y.; Cao, X. Impact of weight loss at presentation on survival in epidermal growth factor receptor tyrosine kinase inhibitors (EGFR-TKI) sensitive mutant advanced non-small cell lung cancer (NSCLC) treated with first-line EGFR-TKI. J. Cancer 2018, 9, 528-534. [CrossRef] [PubMed]

34. Li, W.; Han, L.; Yu, P.; Ma, C.; Wu, X.; Moore, J.E.; Xu, J. Molecular characterization of skin microbiota between cancer cachexia patients and healthy volunteers. Microb. Ecol. 2014, 67, 679-689. [CrossRef] [PubMed]

35. Bindels, L.B.; Delzenne, N.M. Muscle wasting: The gut microbiota as a new therapeutic target? Int. J. Biochem. Cell Biol. 2013, 45, 2186-2190. [CrossRef]

36. Op den Kamp, C.M.; Langen, R.C.; Minnaard, R.; Kelders, M.C.; Snepvangers, F.J.; Hesselink, M.K.; Dingemans, A.C.; Schols, A.M. Pre-cachexia in patients with stages I-III non-small cell lung cancer: Systemic inflammation and functional impairment without activation of skeletal muscle ubiquitin proteasome system. Lung Cancer 2012, 76, 112-117. [CrossRef] 
37. Zhang, F.; Shen, A.; Jin, Y.; Qiang, W. The management strategies of cancer-associated anorexia: A critical appraisal of systematic reviews. BMC Complement Altern. Med. 2018, 18, 236. [CrossRef]

38. Mattox, T.W. Cancer Cachexia: Cause, Diagnosis, and Treatment. Nutr. Clin. Pract. 2017, 32, 599-606. [CrossRef]

39. Baldwin, C.; Spiro, A.; Ahern, R.; Emery, P.W. Oral nutritional interventions in malnourished patients with cancer: A systematic review and meta-analysis. J. Natl. Cancer Inst. 2012, 104, 371-385. [CrossRef]

40. Bayliss, T.J.; Smith, J.T.; Schuster, M.; Dragnev, K.H.; Rigas, J.R. A humanized anti-IL-6 antibody (ALD518) in non-small cell lung cancer. Expert Opin. Biol. Ther. 2011, 11, 1663-1668. [CrossRef]

41. Tseng, Y.C.; Kulp, S.K.; Lai, I.L.; Hsu, E.C.; He, W.A.; Frankhouser, D.E.; Yan, P.S.; Mo, X.; Bloomston, M.; Lesinski, G.B.; et al. Preclinical Investigation of the novel histone deacetylase inhibitor ar- 42 in the treatment of cancer-induced cachexia. J. Natl. Cancer Inst. 2015, 107, djv274. [CrossRef] [PubMed]

42. Liva, S.G.; Tseng, Y.C.; Dauki, A.M.; Sovic, M.G.; Vu, T.; Henderson, S.E.; Kuo, Y.C.; Benedict, J.A.; Zhang, X.; Remaily, B.C.; et al. Overcoming resistance to anabolic SARM therapy in experimental cancer cachexia with an HDAC inhibitor. EMBO Mol. Med. 2020, 12, e9910. [CrossRef] [PubMed]

43. Michaelis, K.A.; Norgard, M.A.; Zhu, X.; Levasseur, P.R.; Sivagnanam, S.; Liudahl, S.M.; Burfeind, K.G.; Olson, B.; Pelz, K.R.; Angeles Ramos, D.M.; et al. The TLR7/8 agonist R848 remodels tumor and host responses to promote survival in pancreatic cancer. Nat. Commun. 2019, 10, 4682. [CrossRef] [PubMed]

44. Suzuki, H.; Asakawa, A.; Amitani, H.; Nakamura, N.; Inui, A. Cachexia and herbal medicine: Perspective. Curr. Pharm. Des. 2012, 18, 4865-4888. [CrossRef]

45. Suzuki, H.; Asakawa, A.; Amitani, H.; Fujitsuka, N.; Nakamura, N.; Inui, A. Cancer cachexia pathophysiology and translational aspect of herbal medicine. Jpn. J. Clin. Oncol. 2013, 43, 695-705. [CrossRef]

46. Katakami, N.; Uchino, J.; Yokoyama, T.; Naito, T.; Kondo, M.; Yamada, K.; Kitajima, H.; Yoshimori, K.; Sato, K.; Saito, H.; et al. Anamorelin (ONO-7643) for the treatment of patients with non-small cell lung cancer and cachexia: Results from a randomized, double-blind, placebo-controlled, multicenter study of Japanese patients (ONO-7643-04). Cancer 2018, 124, 606-616. [CrossRef]

47. Budzynski, J.; Tojek, K.; Czerniak, B.; Banaszkiewicz, Z. Scores of nutritional risk and parameters of nutritional status assessment as predictors of in-hospital mortality and readmissions in the general hospital population. Clin. Nutr. 2016, 35, $1464-1471$. [CrossRef]

48. Mondello, P.; Lacquaniti, A.; Mondello, S.; Bolignano, D.; Pitini, V.; Aloisi, C.; Buemi, M. Emerging markers of cachexia predict survival in cancer patients. BMC Cancer 2014, 14, 828. [CrossRef]

49. Arrieta, O.; Michel Ortega, R.M.; Villanueva-Rodriguez, G.; Serna-Thome, M.G.; Flores-Estrada, D.; Diaz-Romero, C.; Rodriguez, C.M.; Martinez, L.; Sanchez-Lara, K. Association of nutritional status and serum albumin levels with development of toxicity in patients with advanced non-small cell lung cancer treated with paclitaxel-cisplatin chemotherapy: A prospective study. BMC Cancer 2010, 10, 50. [CrossRef]

50. Nishioka, N.; Uchino, J.; Hirai, S.; Katayama, Y.; Yoshimura, A.; Okura, N.; Tanimura, K.; Harita, S.; Imabayashi, T.; Chihara, Y.; et al. Association of Sarcopenia with and Efficacy of Anti-PD-1/PD-L1 Therapy in Non-Small-Cell Lung Cancer. J. Clin. Med. 2019, 8, 450. [CrossRef] 